\section{Optimise post-surgical aftercare}

Help dental implant patients optimise their post-surgical aftercare routine by offering the new Perio Plus+ Regenerate mouth rinse.

This contains the gold standard antiplaque agent, chlorhexidine, which has been naturally enhanced by combining it with CITROX - a powerful anti-microbial, antioxidant and anti-inflammatory substance extracted from bitter oranges. Perio Plus+ Regenerate also contains hyaluronic acid to promote optimal tissue renewal and accelerate the healing process.

Boasting a unique formula that is proven to be more effective than $\mathrm{CHX}$ alone at combatting plaque, Perio Plus+ Regenerate can support patients in protecting against peri-implant mucositis and peri-implantitis.

Call now to start stocking Perio Plus+ products in your practice.

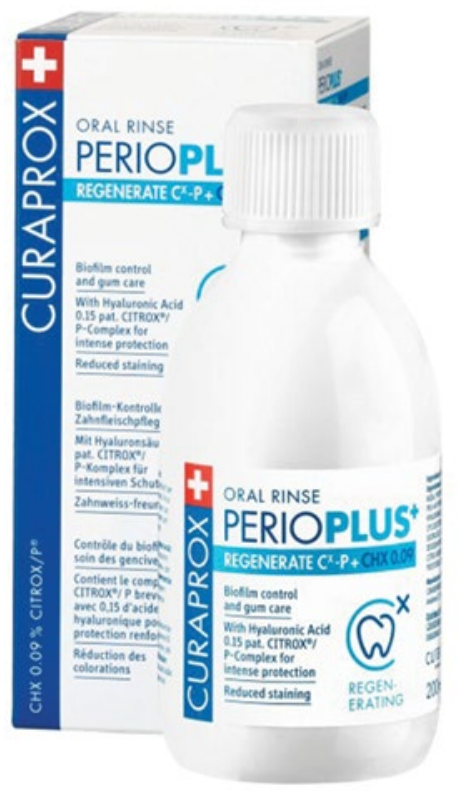

For more information call 01480862084 , email info@curaprox.co.uk or visit www. perioplus.com/uk.

\title{
Helping you keep your foot on the pedal
}

The gradual return to practice has been a trying time in dentistry. The transition has required significant adaptation by all members of the team and patients. As we look to the future, it's important not to take your foot off the pedal to ensure the longterm sustainability of your business.

The next British Dental Conference and Dentistry Show will offer all the support you need to do just this. The diverse educational programme will be presented by an array of experts in different fields. They will offer all the fresh ideas, motivation and guidance you need to help your business not only survive, but thrive.

Save the dates in your diary for 2021.

The next British Dental Conference and Dentistry Show will be held on Friday 21 and Saturday 22 May 2021, Birmingham NEC, co-located with DTS.

For more information, visit www. thedentistryshow.co.uk, call 02073485270 or email dentistry@closerstillmedia.com.

\section{Reliable PPE all in one place}

To make sure you have the right, high-quality PPE in stock to protect you, your staff and your patients, $3 \mathrm{M}$ Oral Care is here to help.

A brand-new website dedicated to all things PPE was recently launched to make it even easier for you to find the products that you need. Simple to navigate, with a wealth of useful information to help you make the best decisions for you and your practice, find all of the below and more at 3M.co.uk/ dental-ppe:

- 3M Aura Particulate Health Respirator FFP2, Type IIR 1862+

- $3 \mathrm{M}$ Aura Disposable Health Respirator FFP3, Type IIR, 1863+

- Surgical Mask 1826
- Splash Resistant Surgical Mask 1820S

- 3M Triple Layer Molded face Mask 2042F

- 3M Cavilon No Sting Barrier Film

- $3 \mathrm{M}$ Comply SteriGage Integrating Indicator.
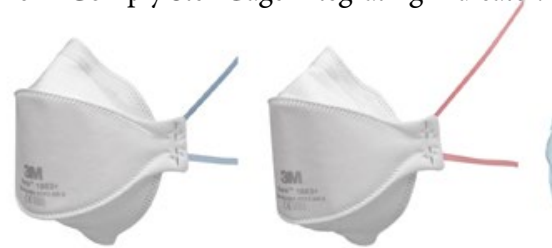

\section{Brushes for every age}

Children's home cleaning routines are more important than ever before. A great routine is regular and uses the right tools and products.

Premium oral hygiene brand Tandex produces high-quality brushes that are comfortable to hold and use.

Tandex has the perfect toothbrush for every patient, from babies to adults. For supervised brushing that won't be a trial, you can help parents select a brush that keeps their child's mouth clean, to start good habits early.

Keeping your youngest patients in good oral health will support their general health and wellbeing. As part of your preventive consultations, talk about Tandex.

For more information on Tandex's range of products, visit www.tandex.dk.

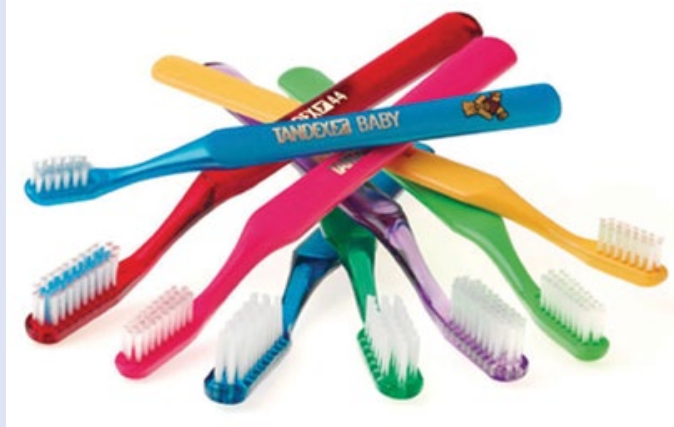

For more information, call 08705360 036 or visit www.3M.co.uk/Dental. $3 \mathrm{M}$ is a trademark of the $3 \mathrm{M}$ Company.

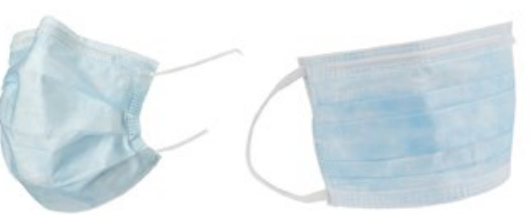

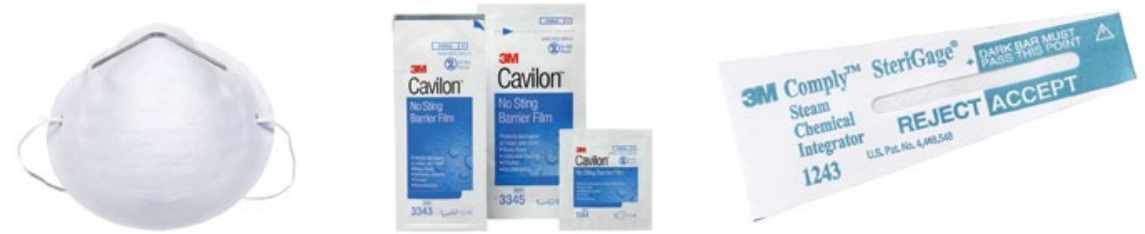

